\title{
Operation Community Impact responds to food insecurity and challenges faced by dairy producers
}

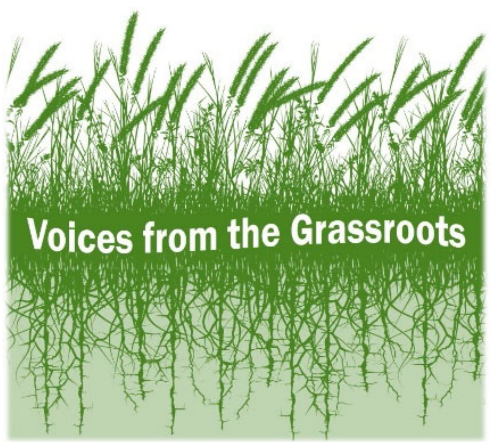

\author{
Stacey F. Stearns a $*$ \\ University of Connecticut Extension
}

William P. Davenport ${ }^{b}$

University of Connecticut Extension

Jennifer E. Cushman ${ }^{\mathrm{c}}$

University of Connecticut Extension

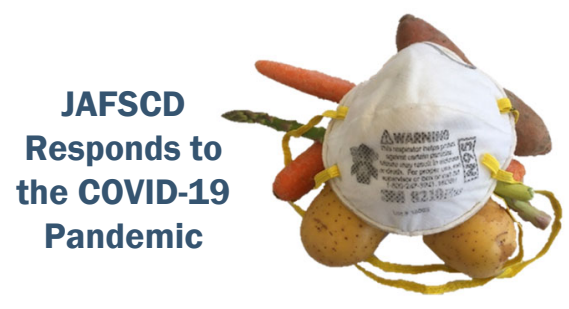

Submitted September 29, 2020 / Published online November 21, 2020

Citation: Stearns, S. F., Davenport, W. P., \& Cushman, J. E. (2020). Operation Community Impact responds to food insecurity and challenges faced by dairy producers. Journal of Agriculture, Food Systems, and Community Development, 10(1), 21-24. https://doi.org/10.5304/jafscd.2020.101.034

Copyright (C) 2020 by the Authors. Published by the Lyson Center for Civic Agriculture and Food Systems. Open access under CC-BY license.

\begin{abstract}
For many individuals and families, challenges surrounding food insecurity increased when the pandemic arrived. COVID-19 also created a surplus of fluid milk and led to decreased prices for farmers. Dairy farms nationwide were dumping milk due to

a * Corresponding author: Stacey F. Stearns, Program SpecialistEducational Outreach, University of Connecticut Extension; 1376 Storrs Road, Unit 4134; Storrs, CT 06269-4134 USA; +1-860-486-9228; Stacey.Stearns@uconn.edu

b William P. Davenport, Assistant Extension Educator, University of Connecticut Extension; William.Davenport@uconn.edu

c Jennifer E. Cushman, Assistant Extension Educator, University of Connecticut Extension; Jennifer.Cushman@uconn.edu
\end{abstract}

decreased demand and lack of storage space at plants. Meanwhile, food pantries were in desperate need of more food to help provide nourishment for the increasing number of individuals facing food insecurity. The Cooperative Extension 4-H and Expanded Food and Nutrition Education Program (EFNEP) programs at the University of Connecticut partnered with dairy processors to secure donations and mobilize Extension volunteers to distribute the donations to food pantries statewide.

\section{Keywords}

COVID-19, Pandemic, Coronavirus, Dairy, Milk, Dairy Surplus, Food Donations, Food Banks, Community Impact, Connecticut 
$\mathrm{O}$ ne of every eight residents in Connecticut struggled with food insecurity before COVID-19 (Feeding America, n.d.). For many individuals and families, challenges surrounding food insecurity were only exacerbated when the pandemic arrived.

COVID-19 created a surplus of fluid milk and led to decreased prices for farmers. Dairy farms nationwide were dumping milk due to decreased demand and lack of storage space at plants. Meanwhile, food pantries were in desperate need of more food to help provide nourishment for the increasing number of individuals with food insecurity.

University of Connecticut (UConn) Extension provided the infrastructure, innovative ideas, and staff support to organize Operation Community Impact. The 4-H Fairboard members in Litchfield County had selected this theme at a January 2020 meeting with the goal of reducing food insecurity in their county. The idea expanded statewide in the midst of the COVID-19 pandemic.

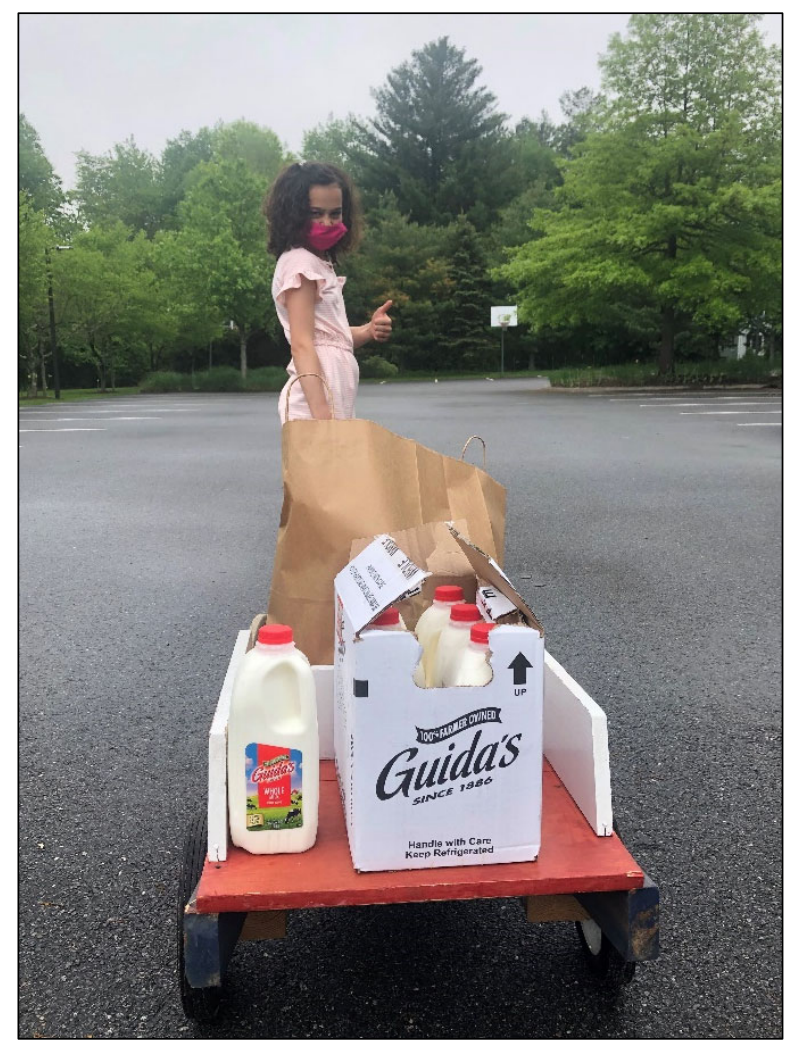

A happy customer transports milk from Guida's Dairy. Photo: Berta Andrulis Mette.
Our 4-H and Expanded Food and Nutrition Education Program (EFNEP) programs partnered with dairy processors to secure donations and mobilize our volunteers to distribute the donations to food pantries statewide.

Volunteers have moved the weight equivalent of 10 full-size elephants since distribution began. Dairy Farmers of America, Agri-Mark Cooperative/Cabot Creamery, and H.P. Hood all donated products. Litchfield County has continued delivering milk every two weeks since March. Residents of Litchfield County have raised over US $\$ 14,000$ in grants and donations to purchase milk for food pantries. To date, Operation Community Impact has:

- Served more than 10,710 families statewide,

- Distributed over 130,000 pounds of dairy products,

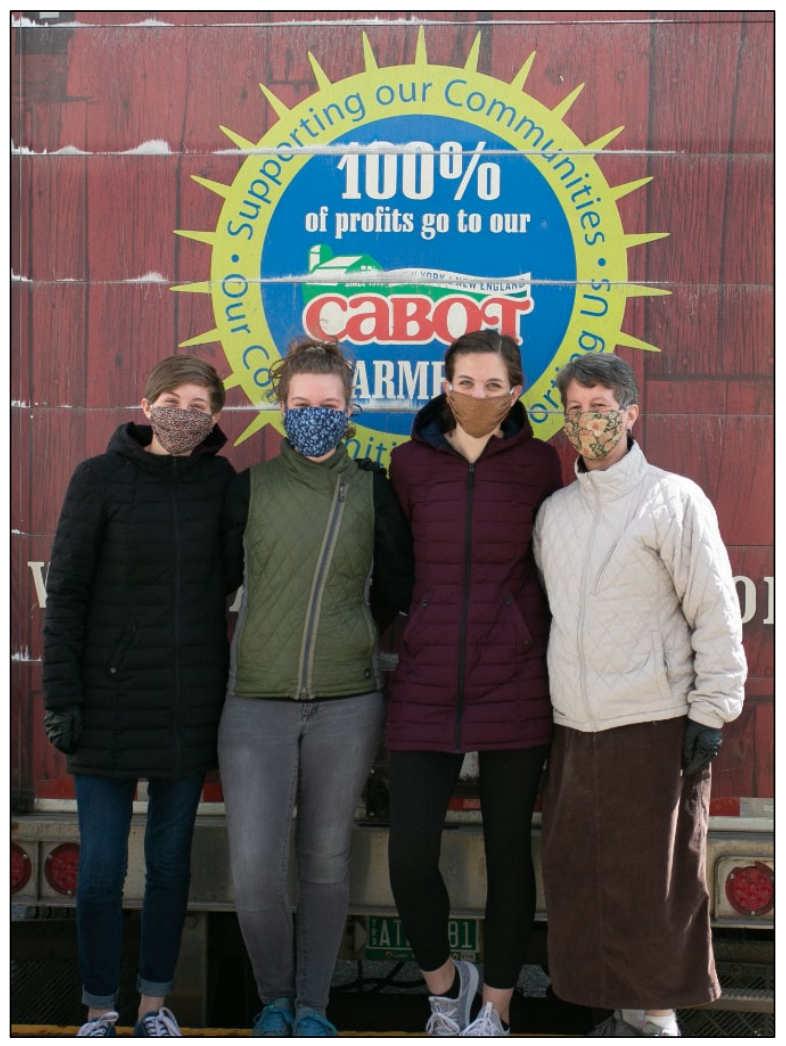

Olivia Hall, Maddie Hall, Ellie Hall and their mom, Peg Hall. Peg is a 4-H Club leader, and all three girls are members and officers in the Litchfield County 4-H Fair Association. The family volunteered at every milk delivery. Photo: Jill Davenport, Litchfield Hills Photography, LLC. 
- Served 96 food pantries,

- Donated to 57 towns statewide, and

- Had 88 Extension families from the UConn College of Agriculture, Health and Natural Resources donate their time and vehicles for distribution.

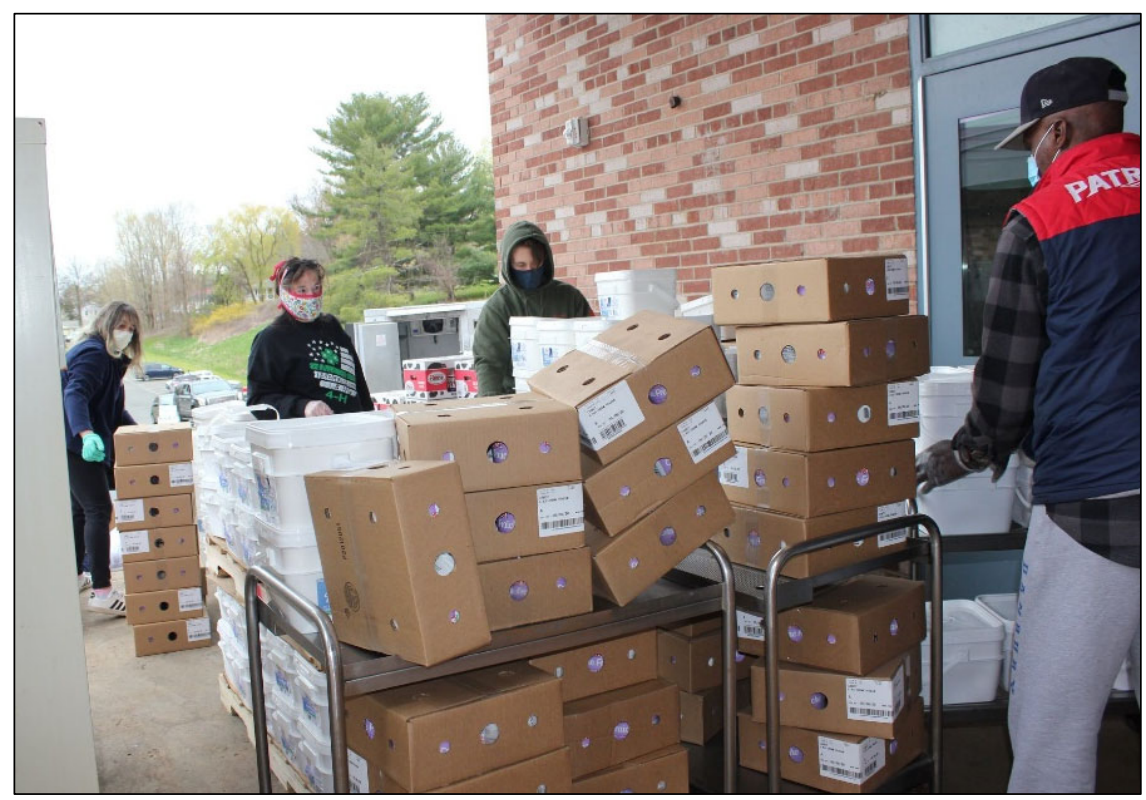

A group of volunteers unloads dairy products donated from Cabot. Photo: Donna Liska, University of Connecticut Extension.

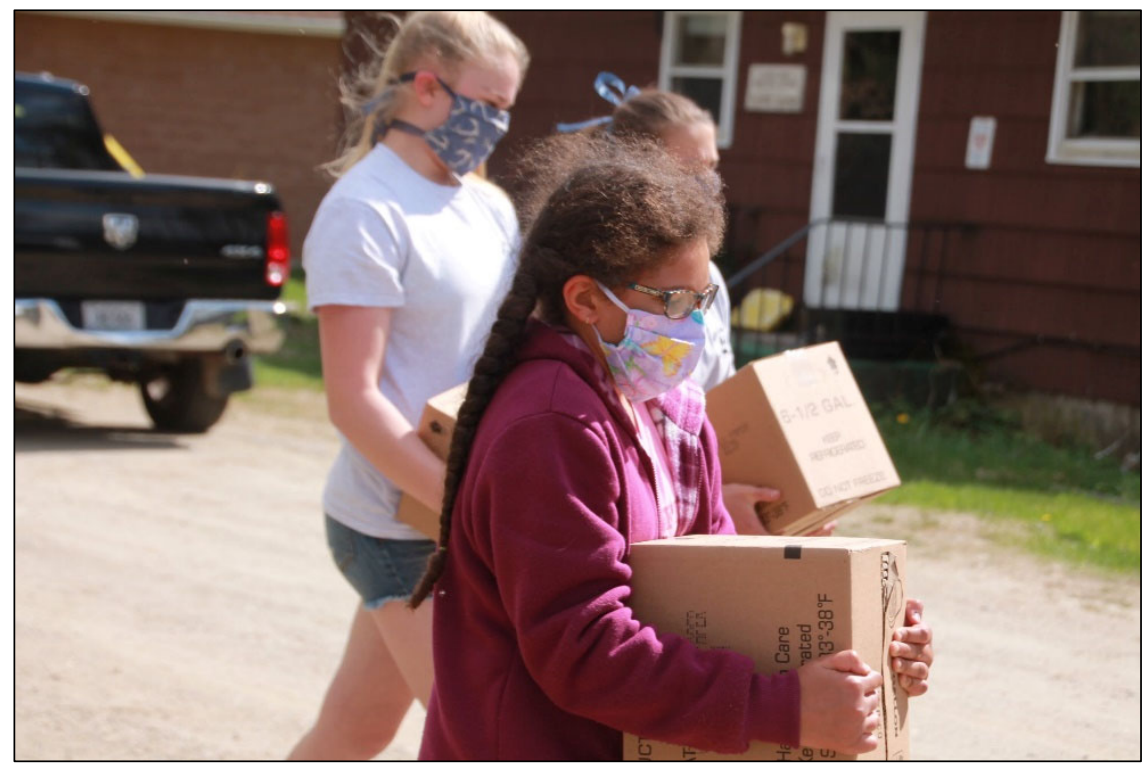

UConn 4-H members carry dairy products from the delivery location to vehicles that transport products to food pantries. Photo: Pamela Gray, UConn Extension.
A group of 4-H members and volunteers, Extension educators, and EFNEP program partners deliver the milk from a central drop off location in each county. Other businesses and partners are donating refrigerated trucks and space. Recipients of the dairy products have expressed their gratitude and shared how much the support means to them.

"My residents are elderly and live on fixed incomes," says Cheryl Herzig, manager of a food pantry in Bantam. "For some, they are not able to purchase the dairy items as there is not enough money. Receiving these donations is a dream come true and a luxury for them to enjoy. Most of these people run out of food by the third week of the month and the food donations help support them and allow them to have a meal. We cannot thank you enough for the availability of these donations. It brings tears to some residents' eyes. Thank you so much for allowing this program for our community."

The Freshplace food pantry in Hartford County stated: "Our Freshplace food pantry serves 100 individuals and families in the North end of Hartford-the poorest neighborhoods in Hartford. Most of our participants do not have access to a grocery store and depend on small bodegas that have a limited supply of dairy products and fresh vegetables. This has become a much larger problem due to the current COVID-19 situation. The delivery of the generous 
donation of milk will help not only our Freshplace participants but many of our other clients who are having a hard time obtaining food. We have expanded our Freshplace services beyond our Freshplace members to encompass all Chrysalis Center clients in need of food. The milk is an incredible addition to our daily deliveries! Thanks so muchthis definitely shows that we are all in this together!"

A Fairfield County food pantry said, "The 115 families that our pantry serves are in significant crisis right now. They are relying on the food pantry for all of their food/meals. Typically, we are very limited in the amounts of dairy products we are able to receive and distribute. The milk, yogurt, and sour cream has made a real impact. Families are now able to add this to their meals, providing a more balanced, nutritional meal and promoting overall health and well-being. THANK YOU!"

Volunteers from many programs participated in the dairy distribution, including 4-H youth members. Several families from Litchfield County have participated in every dairy distribution, often dedicating hours or an entire day away from work for the project. Community service is a key component of the 4-H civic engagement mission. This project provides UConn 4-H members with the opportunity to make a difference in the lives of both consumers and dairy producers.

"Over my seven years in 4-H I have been given many cool community service opportunities, but the dairy outreach community project was by far the most influential," says Madeline Hall, a Litchfield County 4-H member. "It was a huge opera- tion that really helped the community. It was a beautiful sight to see how utterly grateful the pantries and families receiving the milk were. I never knew how many families in Connecticut were in need. I'm so proud to be part of UConn 4-H."

Food insecurity will continue to challenge many residents even after the COVID-19 crisis is over. Our UConn 4-H program is building a sustainable model in which the community members work together to support those in need. The sustained giving from volunteers and donors is supporting our 4-H and EFNEP programs and helping us feed people in communities around the state.

The project results have created new connections in our communities between food pantries and milk processors. The long-term sustainability of the program is helping families in need, increasing milk consumption, and addressing surplus milk issues. It is also making people aware that milk is a local food and that the support of dairy farms has a positive effect in our communities.

Operation Community Impact can be replicated by other dairy cooperatives and organizations. Communities across the country have similar initiatives, and we need to support and expand these efforts. The long-term sustainability and community support will be vital to dairy farmers as they continue adapting to market changes and other situations that arise. Extension can serve as a facilitator for these projects. It has the infrastructure and resources to create connections, as is evidenced by the success of UConn Extension's project.

\section{Reference}

Feeding America. (n.d.). What hunger looks like in Connecticut. Retrieved 2020 from https://www.feedingamerica.org/hunger-in-america/connecticut\# 